Amélia Cohn ${ }^{1}$

Josué Souza Gleriano ${ }^{2}$

\title{
A URGÊNCIA DA REINVENÇÃO DA REFORMA SANITÁRIA BRASILEIRA EM DEFESA DO SISTEMA ÚNICO DE SAÚDE
}

The urgency of reinventing the Brazilian Health Reform in defense of the Brazilian National Health System

${ }^{1}$ Universidade Santa Cecília. Santos/SP, Brasil.

${ }^{2}$ Universidade do Estado de Mato Grosso. Departamento de Enfermagem. Tangará da Serra/MT, Brasil.

Correspondência: Amélia Cohn. E-mail: cohn.amel@gmail.com

Recebido: 20/06/2019. Revisado: 19/01/2020. Nova revisão: 13/03/2020. Aprovado: 03/04/2020. 


\section{RESUMO}

Este artigo teve como objetivo discutir os desafios para a Reforma Sanitária Brasileira e para o Sistema Único de Saúde na atualidade. Resgatou-se a literatura mais atual sobre o tema, recuperaram-se alguns de seus traços fundamentais enquanto processo histórico e de seus atores e remeteu-se à conjuntura política atual no que diz respeito ao Sistema Único de Saúde. A partir de um estudo exploratório de corte histórico fundado na literatura pertinente, o propósito foi fomentar reflexões sobre o tema baseadas naquelas análises sobre o movimento sanitário, contribuindo com novos olhares para a questão da saúde como direito frente aos desafios que o Sistema Único de Saúde enfrenta. Reconheceram-se os avanços do movimento sanitário na construção do sistema, com a ampliação do acesso e da cobertura à atenção à saúde segundo os preceitos da saúde como direito, ao mesmo tempo em que se sinalizaram as limitações históricas para o alcance de seus princípios e diretrizes e as disputas políticas e sociais da atualidade, com vistas a apontar novas possibilidades para a Reforma Sanitária Brasileira. Concluiu-se pela urgência da atualização das propostas originais da reforma, da recuperação de sua dimensão de luta política, da ampliação de alianças com diferentes segmentos sociais em defesa do Sistema Único de Saúde e de retomar a saúde enquanto questão social no interior dos movimentos de resistência democrática, buscando-se novos espaços e sujeitos políticos em defesa do Sistema Único de Saúde.

\section{Palavras-Chave}

Direito à Saúde; Reforma dos Serviços de Saúde; Saúde Pública; Sistema Único de Saúde.

\section{ABSTRACT}

This article focused to discuss the challenges to the Brazilian Health Reform and to the Brazilian National Health System today. Current literature on the subject was reviewed; some of its fundamental features were recovered as a historical process and of its actors, and referred to the current political conjecture regarding the Brazilian National Health System. From an exploratory study historically based on the pertinent literature, the purpose was to encourage reflections on the theme based on those analyzes of the sanitary movement, contributing with new perspectives on the health issue as a right to face the challenges that the SUS faces. The advances of the sanitary movement in the construction of this system were acknowledged, with the expansion of access and coverage to health care according to health precepts as a right, at the same time that the historical limitations to the achievement of its principles and guidelines and current political and social disputes were highlighted, aiming to point out new possibilities for the Brazilian Health Reform. It was concluded that there was an urgent need to update the original proposals for the reform, to recover its dimension of political struggle, to expand alliances with different social segments in defense of the Brazilian National Health System and to resume health as a social issue within democratic resistance movements, seeking new spaces and political subjects in defense of the public system.

\section{Keywords}

Right to Health; Health Services Reform; Public Health; Brazilian National Health System. 


\section{Introdução}

O objetivo do artigo foi revisitar o projeto da Reforma Sanitária Brasileira (RSB), o que significa buscar uma pauta de diálogo, voltada para a ação, com as contribuições formuladas por esse projeto nas últimas décadas. Em decorrência, a tarefa requereu - a partir dos princípios metodológicos que orientam os estudos de recuperação histórica e, portanto, de natureza empírica e analítica da literatura de referência sobre o tema - que o foco de análise recaísse sobre traços das conjunturas sociais que incentivaram esse projeto político e sobre as estratégias para promover avanços nas políticas públicas de saúde voltados ao cumprimento dos mandatos constitucionais de 1988. A partir dessa perspectiva, seria possível vislumbrar ângulos de análise para se pensarem possibilidades atuais da RSB (preocupação central deste texto), que, enquanto movimento dinâmico e contraditório, tem garantido avanços significativos na conquista da atenção à saúde no país, para além de o setor da saúde se constituir progressivamente fator estratégico de desenvolvimento. No decorrer dessa experiência histórica, aqui reconstruída a partir da literatura produzida na área, acrescida de análises da área das ciências sociais, em particular sobre o Brasil, depreendeu-se que ela preserva um de seus traços essenciais desde a origem: o fato de proporcionar e sustentar um campo de produção do conhecimento e de práxis política reconhecido internacionalmente.

$\mathrm{Na}$ atual conjuntura, e com o mesmo horizonte de preocupações, Fleury ${ }^{1}$ chama a atenção para a necessidade de "revisitar a teoria sem subordiná-la aos vícios da crítica meramente ideológica" sobre a capacidade de se articular uma coalização reformista de produção crítica do conhecimento que retome a base conceitual da questão democrática e de sua expansão. Segundo a autora, isto implica um debate audacioso que exponha suas fragilidades, mas pela perspectiva da construção de um discurso emancipatório no campo teórico e político da RSB. Com esse objetivo, a autora aponta que, na produção do campo da saúde coletiva voltada para a RSB, existem lacunas na elucidação de métodos que respaldem a investigação e que, em situações circunstanciais, a análise fica restrita ao âmbito do discurso, reafirmando a necessidade de maior rigor e atenção nas definições dos atores envolvidos no processo e de maior aprofundamento nos aspectos conjunturais das diferentes propostas e análises formuladas e suas implicações no campo político. A autora reconhece a necessidade de distinção entre a dimensão da apropriação analítica realizada pelo campo sanitário e o da dimensão de implantação do Sistema Único de Saúde (SUS) que dá substância à RSB, alertando para que não se perca a perspectiva das estratégias e intervenções sociais que foram e vêm sendo propostas e/ou adotadas.

${ }^{1}$ FLEURY, Sonia. (Org.). Teoria da reforma sanitária brasileira: diálogos críticos. Revisitar a teoria e a utopia da reforma sanitária. Rio de Janeiro: Fiocruz, 2018. p. 31-84. 
Apesar das especificidades de suas interpretações sobre a RSB e das ênfases distintas em suas análises sobre a implementação do SUS, Fleury, Cohn e Paim reconhecem que a produção de conhecimento no âmbito da saúde coletiva sobre o tema tem incorporado a estratégia de concepção e implementação do SUS, embora reconheçam as análises foram progressivamente restringindo seu foco sobre questões relativas à implementação e ao aperfeiçoamento do SUS em sucessivas conjunturas de agravamento das condições para sua concretização. Assim, os estudos passam a enfatizar sobretudo questões gerenciais e organizacionais do SUS no âmbito da administração pública e da formação de quadros gestores; com isso, são deixadas em segundo plano análises propriamente políticas voltadas à sustentação social das propostas da RSB, que, dados os acontecimentos dos últimos anos, requer uma atenção especial e implica revisitar a discussão sobre especificidades da democracia brasileira, com ênfase no campo da análise da política social como aparato material, administrativo e institucional.

É dessa perspectiva que retomamos o texto de $\mathrm{Cohn}^{2}$, com a indagação de fundo sobre os caminhos da RSB: o percurso da construção do SUS em suas três décadas e seu impacto na produção do conhecimento exigem quais tipos de reorientação de perspectiva para nortear estratégias políticas? Pela ótica dos limites enfrentados pela RSB, na conjuntura atual eles apontam para qual direção de potenciais forças de retomada das propostas (atualizadas) do projeto da saúde como direito universal? O objetivo não é trazer respostas estritas a essas perguntas, o que configuraria contrassenso, mas apresentar elementos para reflexão e debate orientados à prática.

\section{A Reforma Sanitária Brasileira: olhares para a crítica}

O esgotamento da proposta da RSB, forjada nas décadas de 1970, 1980 e 1990, dá-se por um conjunto de fatores que anunciam rompimentos e inícios de novos ciclos, por exemplo:

a disputa política cada vez mais acirrada pela definição das diretrizes políticas a serem (ou que na realidade vêm sendo) implantadas na área da saúde, buscando a inversão dos preceitos constitucionais (ao invés do setor privado da saúde ser complementar ao SUS, este se tornar complementar àquele); o fato inédito, desde meados da década de 1970, de os reformistas sanitários terem sido alijados dos postos estratégicos de mando do Ministério da Saúde e de seus similares nos níveis estadual e municipal;

${ }^{2} \mathrm{COHN}$, Amélia. “Caminhos da reforma sanitária”, revisitado. Estud Av, São Paulo, v. 32, n. 93, p. 225241, ago. 2018. Disponível em: http://www.scielo.br/scielo.php?script=sci_arttext\&pid=S010340142018000200225\&lng=pt\&nrm=iso. Acesso em: 10 mai. 2019. https://dx.doi.org/10.5935/0103 4014.20180040. 
a estratégia utilizada pela invasão do sistema de saúde brasileiro pelas denominadas "clínicas de baixo custo", e que com isso não só desvirtuam a relação do setor privado com o SUS (por exemplo, com apenas a apresentação de uma guia de solicitação de exame de diagnóstico prescrita pelo SUS o usuário do sistema se encaminha para essas clínicas, onde realiza o exame solicitado pagando preços "acessíveis" em nome de uma pretensa maior praticidade), como também passam a capturar o imaginário da população, sobretudo dos segmentos populares e de renda média, de como no caso da saúde o privado é mais adequado ao atendimento da sua demanda do que o público ${ }^{3}$.

Compreender o cerne do esgotamento da proposta original da RSB, que optou, como estratégia, pela atuação e ocupação do aparelho do Estado, é essencial para visualizar possíveis caminhos para o futuro. É chegado o momento em que o "aprender a aprender" impõe que se retomem os caminhos da RSB na perspectiva de projetar - para além de seus reais avanços e da sustentação social e política de que ela carece atualmente - possíveis novas fontes de suporte social e, com isso, trazer elementos para definir a direção para buscar propostas de um discurso e de uma prática mais coetâneos da conjuntura contemporânea. As medidas apresentadas recentemente, que acontecem sob o olhar experiente e atento de grupos e segmentos sociais que participaram da trajetória da RSB nas últimas três décadas e que agridem os princípios e diretrizes do SUS, demandam que a atenção se volte para revisitar e compreender os entraves que o ameaçam, não só enquanto projeto de construção de uma rede de seguridade social no país - o que foi mortalmente golpeado já em 1992 -, como também enquanto sistema público e universal de atenção à saúde.

Na dimensão das conquistas da RSB conduzidas pela matriz central da construção e implantação do SUS como estratégia para se fazer cumprir o ditame constitucional ousado da institucionalização da "saúde como direito de todos e dever do Estado", conforme os artigos 196 e 198 da Constituição Federal de 1988 (CF/88) ${ }^{4}$, ficam evidentes os avanços na saúde enquanto direito, apesar das contradições em sua implantação como sistema público de saúde, contaminado desde sua origem por um ambiente político e econômico em que a saúde se revela progressivamente como um bem de consumo individual sob a lógica do mercado 5 .

É a partir dessa ótica que a saúde ganha destaque, em um contexto em que se buscam novos eixos de discussão e reflexão para além dos circuitos acadêmicos, sem o abandono dos rigores do raciocínio lógico e da incorporação dos fatos da

${ }^{3} \mathrm{COHN}$, Amélia. “Caminhos da reforma sanitária”, revisitado, cit., p. 233-234.

${ }^{4}$ BRASIL. Constituição da República Federativa do Brasil de 1988. Disponível em: http://www.planalto.gov. br/ccivil_03/constituicao/constituicaocompilado.htm. Acesso em: 07 jun. 2021.

${ }^{5}$ PAIM, Jairnilson da Silva. Sistema Único de Saúde (SUS) aos 30 anos. ABRASCO. 30 anos do Sistema Único de Saúde (SUS). Ciência e Saúde Coletiva, Rio de Janeiro, v. 23, n. 6, p. 1723-1728, jun. 2018. 
realidade, para possibilitar novas mobilizações e novas práxis na atualidade, articulando forças políticas e sociais em torno da sustentação do SUS.

Torna-se premente identificar possibilidades de articular a sustentação política do SUS em um contexto em que o funcionamento aparente das instituições democráticas está longe de garantir a ordem democrática, condição para que se continue a conquistar a saúde como direito democrático e parte de um projeto civilizatório, conforme assinalava em várias oportunidades Sergio Arouca.

Em resumo, as indagações que nos apresentam na atualidade são: qual é o perfil de participação social, quais sujeitos sociais e espaços (tradicionais e novos) de exercício democrático para a manutenção do direito à saúde são capazes de enfrentar a força dos interesses privados que vêm solapando a lógica da saúde como um bem público - e, nessa condição, pertinente à esfera do interesse público?

Daí a importância de retomar o olhar do líder intelectual e político do movimento sanitário Sergio Arouca para trazer à discussão até que ponto a saúde, como fator isolado, mas associado aos demais fatores no contexto da redemocratização política do país, revelou-se efetivamente como instrumento de um processo civilizatório; por outro lado, até que ponto seus limites são estreitos e limitados, dada a formação do Estado brasileiro, que é patrimonialista, oligárquico e centralizador.

Se o processo de democratização trouxe suficientes janelas de oportunidade para que avanços na modernização do país permitissem abarcar as conquistas na área da saúde ditadas pela $\mathrm{CF} / 88$, ele não tem se revelado robusto o bastante para impedir o avanço, nas arenas de representação e decisão, dos interesses privados no setor da saúde, em grande parte fruto não só de sua força política, como também da progressiva preocupação dos sujeitos "reformistas" com as questões de ordem gerencial e organizacional envolvidas no SUS ${ }^{6}$.

A produção científica tem apontado que o SUS, originalmente concebido como um sistema público universal, estruturou-se como um sistema segmentado e estreitamente articulado com os interesses do mercado no setor público, que impuseram formas de mercantilização em seu interior e na lógica da regulação do próprio setor privado. No âmbito da prestação de serviços pelo setor público, reconhece-se a fragmentação da atenção à saúde tal como estruturada ${ }^{7}$, conduzida por segmentações de toda ordem, acentuadas pela diversidade e pelas desigualdades vigentes no

\footnotetext{
${ }^{6}$ MENDES, Eugenio Vilaça. A construção social da atenção primária à saúde [online]. Brasília: Conselho Nacional de Secretários de Saúde - CONASS, 2015. Disponível em: http://www.saude.go.gov.br/wp-content/ uploads/2016/12/a-construcao-social-da-atencao-primaria-a-saude.pdf. Acesso em: 20 abr. 2019.

${ }^{7}$ FERTONANI, Hosanna Pattrig; PIRES, Denise Elvira; BIFF, Daiane; SCHERER, Magda Duarte dos Anjos. The health care model: concepts and challenges for primary health care in Brazil. Ciênc Saúde Coletiva, Rio de Janeiro, v. 20, n. 6, p. 1869-1878, jun. 2015. Disponível em: http://www.scielo.br/scielo.php?pid=S141381232015000601869\&script=sci_abstract. Acesso em: 10 mai. 2019. http://dx.doi.org/10.1590/141381232015206.13272014.
} 
país e que dificultam a construção da representação social da atenção à saúde para além da assistência médica; como consequência, a constituição da representação social da saúde como direito de todos e responsabilidade do Estado torna-se mais difícil, bem como a compreensão de que ela venha a ser desempenhada por meio do SUS enquanto sistema público, universal, equânime e com prestação de serviços que respeitem a integralidade da atenção à saúde - portanto, destinado a todos os cidadãos. Isso se contrapõe à representação social do acesso à saúde na forma de um seguro destinado aos segmentos pobres da sociedade, noção frequentemente retomada pelos interesses privados contemplados nas propostas neoliberais, resguardando-se as classes de média e alta renda para o segmento lucrativo do sistema de saúde; registre-se que essas classes só recorrem ao sistema público de saúde nos procedimentos de alto custo, concorrendo, então, com os usuários correntes do SUS.

Faz-se necessário, assim, retomar o lema "saúde como um bem comum, e não mercadoria" e buscar novos olhares para desmistificar a afirmação, transformada em dogma, da ineficiência do Estado - porque público -, cabendo a garantia dos direitos e da qualidade na atenção à saúde (entendida como assistência médica) à privatização do SUS, o que significa seu desmonte; bem como buscar pensar para além dos trajetos já percorridos e da agenda definida para o Estado pelos interesses privados financistas e recompor uma proposta da real função do aparelho público estatal na condução de suas instituições.

Mas a questão não se restringe ao Executivo. Também um olhar atento para o Poder Legislativo vai mostrar que essa instância não abraça a causa da saúde como um direito; que suas investidas apontam para um caminho oposto a este, de forma a servir não só os interesses imediatos do mercado, mas também a avançar na desconstrução de pontos e teses fundamentais da RSB enquanto projeto político. Fica evidente que, nesse âmbito, o caminho da negociação política distancia-se das políticas redistributivas e reforça posicionamentos de uma bancada pró-mercado da saúde. Assim, é pertinente reconhecer que o setor privado da saúde não visa a pôr fim ao SUS nem somente desconstruí-lo, como ocorreu na gestão Temer (20162018), mas destruí-lo tal como originalmente formulado com diretrizes e princípios. Daí ser estratégica a busca de formas políticas e sociais de sustentação do SUS para garantir a saúde como um direito de todos.

De forma complementar e articulada, o terceiro poder da República, Judiciário, vem respondendo coniventemente com a concepção da saúde como um bem individual de consumo em detrimento de um bem coletivo. Isso fica evidente nas sentenças proferidas nos processos de demandas judiciais da saúde, sejam eles contra o setor privado, sejam eles contra o setor público ${ }^{8}$.

8INSPER. Judicialização da saúde no Brasil: perfil das demandas, causas e propostas de solução. Brasília: Instituto de Ensino e Pesquisa -2019. (Relatório Analítico Propositivo Justiça Pesquisa). Disponível em: https:// static.poder360.com.br/2019/03/relatorio-judicializacao-saude-Insper-CNJ.pdf. Acesso em: 15 abr. 2019. 
Assim, os três poderes da República, na contramão da defesa dos interesses do SUS e da constituição da saúde como um direito, exigem da RSB não só olhares e diálogos críticos, mas o resgate do olhar para a sociedade brasileira, que vem sendo confrontada nos anos mais recentes pela nova configuração política e a decorrente atuação do Executivo, marcada por um modelo de necropolítica ${ }^{9}$ - vale dizer, seja por meio do uso da força, seja pela omissão do Estado em casos de conflito (como acontece contra os indígenas), seja por meio de cortes orçamentários na área social e na forma de implementação das políticas sociais, configurando o exercício do poder instituído como instância que define na sociedade "quem é descartável e quem não é”. Na atual conjuntura do país, essas formas de exercício do biopoder vêm se apresentando com sua face mais crua e brutal, tal como analisa Mbembe ${ }^{10}$ tratando empiricamente sobre outras realidades.

Assumir a tarefa de trazer elementos para recriar a mobilização social em torno da questão da saúde exige coragem, mas também certo grau de disposição para o desencanto, pois a atual realidade configura-se nebulosa quanto a encontrar traços de generosidade e solidariedade sociais. Daí se reafirma a premência do esforço para identificar novos segmentos sociais que se reconheçam, ou possam a vir se reconhecer, nas propostas da RSB - tarefa complexa, dada a necessidade de atualizar seu conteúdo e seu discurso a fim de que façam sentido para os sujeitos sociais desta sociedade tão fragmentada e violenta, agora de forma explícita.

Isso implica questionar como retomar a proposta de um Estado propositivo, associado à sociedade, e não inimigo dela, e que seja capaz de mobilizar estruturas articuladas voltadas para a construção emancipatória da consciência cidadã, em que o conceito ampliado de saúde, que valoriza suas determinações sociais, constitua o fundamento das políticas públicas no setor, podendo favorecer rupturas com a lógica consumista de serviços de saúde e apontando para o reforço da perspectiva da promoção da saúde.

Os princípios doutrinários do SUS - universalidade, equidade e integralidade - precisam ser incorporados na perspectiva do ciclo da cidadania social, defrontando-se com o monopólio dos interesses do capital na política e no Estado ora vigente. Olhar para o aparelho do Estado na atual conjuntura é reconhecer que há limites na estratégia política até aqui adotada, que no presente momento se veem acentuadas, e que ameaçam tanto a tentativa de se caminhar na perspectiva dos princípios doutrinários do SUS como de assegurar um Estado democrático de direito que respeite e promova um desenvolvimento da sociedade orientado pelos preceitos dos direitos humanos.

O foco deslocado para as especificidades da sociedade civil no Brasil leva ao retorno da participação social e do lugar que ela vem ocupando enquanto

${ }^{9}$ MBEMBE, Achille. Necropolítica. São Paulo: N-1 edições, 2018.

${ }^{10}$ Id.Ibid. 
representação de interesses dos distintos segmentos sociais, em uma sociedade marcada por profundas desigualdades. Desigualdades estas que passam a ser, depois de quase duas décadas na busca de seu enfrentamento, radicalmente reproduzidas de forma recorrente e que, de forma explícita, capilarizam os interesses do capital, sobretudo financeiro, nas estruturas privada e pública estatal da saúde, indo de encontro às prioridades da atenção à saúde conformadas pelas demandas e necessidades sociais de uma realidade complexa, fragmentada e, atualmente, polarizada.

As desigualdades sociais, que tem a desigualdade de renda como vetor transversal das demais desigualdades que marcam os distintos segmentos, não permitem mais, para sua plena compreensão, que esses segmentos sejam diferenciados em termos de pertencimento a classes sociais, a classes de renda; tampouco a diferenciação por classes de carências é capaz de dar conta da identidade social desses segmentos. Apreender essas desigualdades em toda sua complexidade torna-se um desafio não só para os gestores das políticas públicas de saúde, como também para analistas, sujeitos políticos e, consequentemente, para as lideranças e os sujeitos envolvidos na RSB e na busca de identificação de novos caminhos para a defesa do SUS.

\section{Retomando diálogos e assumindo novos olhares}

Para reorientação de projetos e agendas, Tatagiba ${ }^{11}$ aponta que conjunturas de crise constituem oportunidade solidária e de autorreflexão acerca dos objetos, métodos e padrões para sua explicação; no caso brasileiro, a atual crise da democracia no país demanda esforços no sentido de compreender e antecipar mudanças sociais presentes no presente cenário. Por isso, revisitar o campo fragilizado da democracia brasileira, olhada por O’Donnell em 1986 como "languidamente elitista" 12 , revela-se um recurso privilegiado para atentar às mudanças em curso e à necessidade de se investir em projetos emancipatórios com base na participação social. Trata-se de uma convocatória do próprio movimento da RSB à sociedade civil: que se reconheça, no âmbito coletivo, o sistema público de saúde brasileiro como esfera da seguridade social.

Traçar esse percurso, dadas as fragilidades de convencimento no discurso da emancipação, será um dos maiores desafios para o projeto da RSB, para além da organização da sociedade tendo como eixo fundamental as necessidades sociais fundamentais, dentre elas o direito à saúde, sobretudo em um contexto de restrição orçamentária que não só compromete o funcionamento do SUS, como reduz

\footnotetext{
${ }^{11}$ TATAGIBA, Luciana. Os protestos e a crise brasileira. Um inventário inicial das direitas em movimento (2011-2016). Sinais Sociais, Rio de Janeiro, v. 11, n. 33, p. 71-98, jan./abr. 2017. Disponível em: http:// www.sesc.com.br/wps/wcm/connect/3daaa858-e528-4f0b-b12a-e115803bf073/SinaisSociais_SS33_ WEB_14_09_17.pdf?MOD=AJPERES\&CACHEID=3daaa858-e528-4fOb-b12a-e115803bf073. Acesso em: 10 mai. 2019.

${ }^{12} \mathrm{COHN}$, Amélia. “Caminhos da reforma sanitária”, revisitado, cit., p. 225-241.
} 
acentuadamente sua capacidade de resposta às necessidades da população usuária, o que, por sua vez, enfraquece a convicção no discurso de defesa do próprio sistema.

Daí a atualidade da carta de Sérgio Arouca para Eleutério Rodriguez Neto, convidando-o a revisitar o projeto da RSB.

Dezessete anos depois da $8^{\mathrm{a}}$, novamente presidente da comissão organizadora, o tema da Conferência anda em torno de um novo ciclo de reformas. Você sabe o quanto nos dedicamos a construir o Sistema Único de Saúde (SUS), perdendo de vista a reforma sanitária e, mais ainda, como nos tempos difíceis acabamos blindando o SUS para resistir aos ataques neoliberais e conservadores. Está na hora de fazer uma análise crítica bem-feita e dar um salto de qualidade. Não vai dar para você escrever um texto orientador das discussões, mas tem bastante material seu apontando os nós e as consequências das estratégias possíveis que utilizamos ${ }^{13}$.

Até então, as respostas formuladas pelo movimento sanitário ainda se mostravam incipientes para dar conta da envergadura da implantação das propostas da RSB, o que desde finais dos anos 1980 já vinha sendo apontado ${ }^{14}$. A trajetória das três primeiras décadas do SUS é marcada pela precariedade inicial na elaboração de propostas de organização e dinâmica institucionais do sistema, seja no campo de conhecimento da saúde coletiva, seja no âmbito da administração pública, o que acabou se refletindo no desencontro entre a proposta formulada inicialmente e a posterior atuação institucional do Estado e de seus serviços ${ }^{15}$, que reconstroem constantemente aquela proposta.

Daí a pertinência de se resgatarem, no campo político-institucional, os caminhos das narrativas que, via de regra, originaram o movimento sanitário na década de 1970, culminando na criação do Centro Brasileiro de Estudos de Saúde (Cebes), em 1976, e da Associação Brasileira de Pós-Graduação em Saúde Coletiva (Abrasco), em 1979, representados por atores que começaram a atuar em posições estratégicas no interior das agências estatais e voltados a introduzir mudanças progressivas na organização do sistema de saúde brasileiro ${ }^{16}$.

${ }^{13}$ AROUCA, Antônio Sérgio da Silva. Deu certo! Saúde Debate, Rio de Janeiro, v. 28, p. 75-77, 2003.

${ }^{14}$ OLIVEIRA, Jaime A. A saúde pública hoje: notas para um debate sobre a conjuntura em saúde e a situação da ENSP ao seu interior. Cad. Saúde Pública, Rio de Janeiro, v. 4, n. 3, p. 326-333, set. 1988. Disponível em: http://www.scielo.br/scielo.php?script=sci_arttext\&pid=S0102-311X1988000300007. Acesso em: 10 mai. 2019. http://dx.doi.org/10.1590/S0102-311X1988000300007.

${ }^{15}$ SILVEIRA, Lucas Bronzato. A produção teórica da saúde coletiva brasileira na década de 90: texto, contexto e mudança social. 2015. Dissertação (Mestrado) - Escola Nacional de Saúde Pública Sergio Arouca, Fundação Oswaldo Cruz, Rio de Janeiro, 2015. Disponível em: https://www.arca.fiocruz.br/handle/ icict/13476. Acesso em: 10 mai. 2019.

${ }^{16}$ PAIVA, Carlos Henrique Assunção; TEIXEIRA, Luís Antonio. Reforma sanitária e a criação do Sistema Único de Saúde: notas sobre contextos e autores. Hist, Ciênc, Saúde-Manguinhos, Rio de Janeiro, v. 21, n. 1, p. $15-$ 35, jan./mar. 2014. Disponível em: http://www.scielo.br/pdf/hcsm/v21n1/0104-5970-hcsm-21-1-00015. pdf. Acesso em: 10 mai. 2019. 
É reconhecida a importância de os profissionais de saúde "sanitaristas" ocuparem espaços no interior do aparelho estatal que o projeto da RSB permeava, com inciativas indutoras de novas práticas institucionais que se conjugassem com o projeto da agenda reformista do Estado. Essa é uma questão importante, a ser levada em conta enquanto estratégia de luta na atualidade. Isso porque, no passado, esse movimento de ocupação do Estado deu-se em sincronia com a presença de um quadro de profissionais de saúde já politicamente formados na militância partidária ou na mobilização pela redemocratização do país e, em seguida, por cursos de especialização sanitarista. Assim, repensar a refundação da RSB implica pensar o campo da gestão da saúde, inclusive da prestação direta de serviços, como alvo de um novo esforço de repolitização da gestão, criando novas modalidades e novos espaços de participação social e envidando esforços para a identificação de "novos" sujeitos sociais e modalidades de exercício democrático em torno do direito à saúde.

Para tanto, não basta retomar o debate em torno das clássicas teorias da sociedade de classes, nos moldes clássicos da sociedade do trabalho, e das novas teorias da sociedade fluida, na atual conjuntura fundada pela precariedade do trabalho e pela individualidade. É preciso reconhecer que o capitalismo da atualidade - vale dizer, sua forma de acumulação de capital - gera uma sociedade individualizada, na qual o egoísmo se sobrepõe à solidariedade social como ethos predominante, traduzindo-se em novas relações sociais e de legitimação do poder que desafiam as tradicionais modalidades de participação democrática nos processos de tomada de decisão e de implementação de políticas públicas, dos quais se valeu o movimento da RSB e que hoje veem seu potencial de efetividade comprometido. Não basta substituir as ruas e os conselhos gestores (na atualidade ameaçados) por redes sociais. Os tempos exigem o resgate e a reinvenção de uma política propositiva, a ser praticada em múltiplos espaços da sociedade.

No entanto, no texto já citado Fleury ${ }^{17}$ aponta que houve um processo de modernização sem modernidade no Brasil; e Florestan Fernandes, em seu clássico e fundamental estudo de meados de 1970, já denominava uma revolução burguesa inacabada ${ }^{18}$, desenhando uma ordem democrática capitalista avessa à democracia, enquanto ordem política, e, em decorrência, à implementação de políticas públicas e de saúde. Disso emerge um novo foco, nunca negligenciado pelo movimento da RSB, mas que talvez, na atual conjuntura, deva ganhar destaque especial enquanto espaço a ser conquistado na busca de avanços na resistência em defesa do SUS, com seus princípios e diretrizes: 0 campo das bases materiais e simbólicas da produção do cuidado pelo sistema de saúde.

A disputa dos projetos para a saúde que estão no tabuleiro não se restringe àquela dada pela ganância do interesse privado junto ao fundo público, justificado enquanto suporte à proposta de universalização, mas também, e sobretudo, por

\footnotetext{
${ }^{17}$ FLEURY, Sonia. (Org.). Teoria da reforma sanitária brasileira: diálogos críticos. op. cit.

${ }^{18}$ FERNANDES, Florestan. A revolução burguesa no Brasil. Rio de Janeiro: Zahar, 1975.
} 
novas posturas e atitudes dos profissionais de saúde frente aos usuários do SUS. É disputar o discurso e a prática na prestação dos serviços com novos parâmetros de eficácia social, respeitada a efetividade das políticas e dos programas - eficácia social esta pautada por princípios de solidariedade social e, portanto, de autonomia dos sujeitos sociais enquanto portadores de direitos.

Reconhece-se, porém, que neste ponto os limites de atuação são estreitos, pois, como já assinalava Streeck ${ }^{19}$, o mercado dita o que o Estado democrático pode fazer em termos de cobertura da população e o que pode dela retirar. Há de se distinguir que, no campo da disputa da saúde e para além do projeto da RSB, transitam projetos com propostas mercantilistas ou expansionistas, revisionistas ou racionalistas $^{20}$. Não por acaso, o setor das empresas médicas que realizam a intermediação da assistência à saúde, justificadas como proposta de parceria virtuosa de articulação público-privado no favorecimento do acesso dos cidadãos à atenção à saúde, tem ganhado força e peso político, com inserção privilegiada no sistema de saúde, que, por sua vez, está sob crescente dominância do capital financeiro ${ }^{21}$. Com isso, vê-se comprometida a capacidade de regulação do Estado sobre o setor, até há poucas décadas garantida pelo fato de o Estado ser o maior comprador dos serviços privados de saúde.

Em um movimento paradoxal e contraditório, que é a marca das conquistas na saúde a partir de 1988, o mercado instalou-se de forma consolidada ao mesmo tempo em que o SUS era implantado, não se tratando mais de mera presença de um sistema privado de produção de serviços de saúde robusto, financiado pelo Estado. Trata-se, na atualidade, do transplante da lógica privada do cálculo econômico para o interior do sistema público estatal da saúde. Não se trata mais, portanto, de meras disputas doutrinárias; apesar de sua relevância ideológica, essa disputa revela-se agora insuficiente, dada a magnitude da ganância dos interesses do capital, predominantemente sua fração financeira.

O SUS vem se constituindo permeado pela disputa ideológica, dentre outras, entre universalização e focalização do acesso à saúde, associada à abrangência dos serviços a que a população teria acesso. Essa tensão permanente, que desafia os eixos do próprio projeto da RSB de ação do Estado a favor do SUS, tem assegurado

${ }^{19}$ STREECK, Wolfgang. The crisis of democratic capitalism. New Left Review, Reino Unido, v. 71, p. 5-29, set.-out. 2011. Disponível em: https://newleftreview.org/issues/II71/articles/wolfgang-streeck-the-crisesof-democratic-capitalism. Acesso em: 10 mai. 2019.

${ }^{20}$ PAIM, Jairnilson da Silva. A reforma sanitária brasileira e o Sistema Único de Saúde: dialogando como hipóteses concorrentes. Physis, Rio de Janeiro, v. 18, n. 4, p. 625-643, 2008. Disponível em: http://www. scielo.br/scielo.php?script=sci_arttext\&pid=S0103-73312008000400003\&lng=en\&nrm=iso. Acesso em: 10 maio 2019 http://dx.doi.org/10.1590/S0103-73312008000400003.

${ }^{21}$ SESTELO, José Antonio de Freitas. Planos e seguros de saúde do Brasil de 2000 a 2015 e a dominância financeira. 2017. Tese (Doutorado) - Programa de Pós-Graduação em Saúde Coletiva, Universidade Federal do Rio de Janeiro, Rio de Janeiro, 2017. Disponível em: http://www.iesc.ufrj.br/gpdes/images/arquivos/ Tese---Jos-Sestelo.pdf. Acesso em: 10 mai. 2019. 
direitos da cidadania em processos focalizados de inclusão de agendas na saúde, enquanto fortalece a relação público-privado no interior da própria estrutura legal voltada à gestão do sistema de saúde. Na atual conjuntura, a disputa pelo poder por parte dos sanitaristas, que antes se centrava em incluir a agenda da RSB na pauta do Estado, seja pelo esvaziamento de sua organização, seja pela diminuição drástica de sua representatividade no interior do aparelho estatal, não consegue mais se traduzir em uma presença política efetiva e proativa dos sanitaristas do campo da saúde enquanto atores técnico-políticos. De fato, os gestores hoje, em sua maioria, não se reconhecem mais como militantes da RSB, mas como militantes do SUS; e, nessa condição, voltam sua responsabilidade e sua atenção à dimensão técnico-financeira do funcionamento do sistema, em detrimento da dimensão política de sua persistência e avanço.

Simultaneamente, surgem propostas de outro sistema de saúde para se contrapor ao SUS: a criação de um Sistema Nacional de Saúde, entendido como híbrido em sua estrutura nuclear, selando a parceria perversa, e que vem sendo afiada entre os setores público e privado na saúde em detrimento do Sistema Único de Saúde ${ }^{22,23}$.

É nesse contexto que os segmentos sociais comprometidos com o projeto inicial da reforma sanitária estão voltando à cena, embora dela nunca tivessem desertado. Mas, agora, voltam à cena desafiados pela nova conjuntura política e social do país, em que os espaços de luta e de disputa não são mais óbvios. Talvez nunca o tenham sido, mas também nunca antes tão nebulosos.

Resgatando alguns elementos da RSB no final dos anos 80 do século passado. A Assembleia Nacional Constituinte e o SUS foram conquistados nas ruas; ali presentes, sujeitos bem definidos em termos de sua situação de classe (acadêmicos, estudantes da área da saúde, sindicalistas do campo e da cidade, movimentos sociais da saúde e movimentos populares em geral, movimentos eclesiais de base vinculados à Igreja Católica, dentre outros). No entanto, no decorrer desses 30 anos, verifica-se que o movimento político mobilizado em torno da saúde acabou por progressivamente se desidratar em termos de abrangência social, tornando-se cada vez mais distante da sociedade e, assim, acentuando um dos seus traços iniciais, de promoção de uma reforma "pelo alto".

\footnotetext{
${ }^{22}$ MATHIAS, Maíra. Uma segunda alma para o SUS? Entidades criadas por empresários da saúde abrem caminho para um Sistema Único totalmente integrado e gerido pelo setor privado. Escola Politécnica de Saúde Joaquim Venâncio, 09 nov. 2016. Disponível em: http://www.epsjv.fiocruz.br/noticias/reportagem/ uma-segunda-alma-para-o-sus. Acesso em: 12 maio 2019.

${ }^{23}$ BAHIA, Ligia; SCHEFFER, Mario. O SUS e o setor privado assistencial: adaptações e contradições. Saúde Debate, Rio de Janeiro, v. 42, n. especial 3, p. 158-171, nov. 2018. Disponível em: http://www.scielo.br/ scielo.php?script=sci_arttext\&pid=S0103-11042018000700158\&lng=en\&nrm=iso. Acesso em: 10 mai. 2019. http://dx.doi.org/10.1590/0103-11042018s312.
} 
Escorel $^{24}$, já no final dos anos 1990, apontava que a prática utilizada pelo movimento sanitário de ocupação dos espaços institucionais no interior do aparelho do Estado, ao mesmo tempo em que os transformava em lócus de militância e de construção substantiva do novo projeto para a saúde, significava o distanciamento de suas bases sociais - em particular, do movimento popular - por priorizar a tática de um processo restrito quase que exclusivamente aos espaços político-legais ou jurídico-institucionais. À época, isso fazia todo sentido, dada a natureza do processo brasileiro de transição democrática - que, embora tenha contado com robusta mobilização social, também foi feito "pelo alto"; perdeu-se, com isso, a capacidade de aliança com as classes populares, tão necessária na contemporaneidade. Dessa opção política de atuar cada vez mais em nome da população, e não em articulação orgânica com os setores populares, gerou-se um dilema reformista. Em 2005, Escorel, Nascimento, Edler ${ }^{25}$ endossam essa estratégia; Fleury ${ }^{26}$, na coletânea já citada, retoma seus textos datados daquela época para igualmente reafirmar essa posição, ressalvando que hoje é necessário debruçar-se sobre as teorias acumuladas a respeito da reforma sanitária brasileira e analisá-las criticamente. Paim ${ }^{27} \mathrm{faz}$ algo similar e volta ao tema da perspectiva dialética, a partir da qual distingue, em sua análise, o movimento sanitário de "sua criação" (a Reforma Sanitária).

Interessante que, em vários textos atuais que revisitam as teorias e práticas que caracterizaram a RSB, um autor persista como embasamento das "velhas" análises, ou as seminais, e das atuais: Gramsci. Como apontam Bahia e Scheffer,

Para uns, o núcleo das transformações da Reforma Sanitária consistia na necessidade de travar a batalha por consciência da determinação social sobre o processo saúde-doença. Assim, tratava-se de gramscianamente realizar mudanças radicais na consciência e práticas. Para outros, a concepção de reforma e não ruptura parecia inadequada às condições concretas do país e sua inserção periférica. Em termos práticos, uma das vias propostas para a reforma, a via congressual, a Assembleia Nacional Constituinte, afigurava-se como uma alternativa por $\operatorname{cima}^{28}$.

No entanto, ao se analisar o processo da RSB, faz-se necessário vislumbrar janelas de oportunidade avançar a RSB nestes tempos em que elas se fecham no

\footnotetext{
${ }^{24}$ ESCOREL, Sarah. Reviravolta na saúde: origem e articulação do movimento sanitário, 1. ed. Rio de Janeiro: Fiocruz, 1999.

${ }^{25}$ ESCOREL, S.; NASCIMENTO, D. R.; EDLER, F. C. As origens da reforma sanitária e do SUS. In: LIMA, Nísia Trindade; GERSCHMAN, Silvia; EDLER, Flavio Coelho; SUÁREZ, Julio Manuel (Orgs.). Saúde e democracia: história e perspectivas do SUS. Rio de Janeiro: Editora Fiocruz, 2005. p. 59-81.

${ }^{26}$ FLEURY, Sonia. (Org.). Teoria da reforma sanitária brasileira: diálogos críticos. op. cit.

${ }^{27}$ PAIM, Jairnilson da Silva. Sujeitos da antítese e os desafios da práxis da reforma sanitária brasileira. In: FLEURY, Sonia (Org.). Teoria da reforma sanitária brasileira: diálogos críticos. Rio de Janeiro: Fiocruz, 2018. p. 115-144, especialmente p. 97-98.

${ }^{28}$ BAHIA, Ligia; SCHEFFER, Mario. op. cit., p. 161.
} 
interior do aparelho do Estado. De fato, fenômeno inédito nos últimos 30 anos é o despejo dos quadros sanitaristas (que se confundem com os quadros da RSB) do aparelho estatal. Se no início a pretensão era, por meio de uma reforma, instaurar um sistema de saúde universal em um ambiente democrático, na atualidade o desafio consiste em como resistir e, também, em como fazer avançar as conquistas obtidas pelo êxito da empreitada da RSB, porém em um contexto em que não só não se dispõe mais dos espaços no interior do aparelho do Estado, como o próprio Estado tornou-se o inimigo da sociedade.

Neste ponto, registre-se que os conselhos de saúde, espaços onde se forjaram propostas pioneiras de luta política entre a autonomia dos movimentos sociais frente ao Estado e sua participação institucional, estão sendo paulatinamente esvaziados, não só enquanto prática de política pública, mas com a extinção de todos aqueles sem garantia constitucional para sua existência ${ }^{29}$. De certa forma, num movimento igualmente dialético e contraditório, enquanto no início da RSB a defesa da participação popular em espaços institucionais como forma de conquistar legitimidade social e política para as decisões inovadoras no âmbito da saúde se contrapunha a uma visão empresarial de produção das políticas no setor ${ }^{30}$, na atualidade o desafio consiste em como retomar a RSB por fora do Estado. Há que se registrar, contudo, que, apesar do enorme significado político e social da experiência da participação dos segmentos organizados da sociedade na gestão pública por meio dos conselhos de participação social, ela revela a presença da tendência de um processo de captura dos conselheiros representantes da sociedade naqueles espaços, associado a um processo crescente de despolitização desses conselhos, agora via um mecanismo clássico dos regimes autoritários, qual seja, a substituição da política pela técnica e pelo discurso tecnocrático desprovido de qualquer embasamento concreto, a exemplo das atuais propostas para a área da saúde mental que afrontam diretamente a reforma psiquiátrica no Brasil.

Foi a partir do ideário participativo que marca o processo de democratização no país, com a criação de espaços institucionais de participação, estudados e analisados em profusão por estudiosos da democracia brasileira no período recente, que a representação social no setor da saúde construiu elos (que hoje se revelam tênues diante da magnitude do desafio que se apresenta) com a sociedade civil, no sentido de fortalecimento da dimensão propriamente política desses sujeitos sociais frente ao Estado ${ }^{31}$.

\footnotetext{
${ }^{29}$ BRASIL. Decreto n. 9.759, de 11 abril de 2019. Extingue e estabelece diretrizes, regras e limitações para colegiados da administração pública federal. Disonível em: http://www.planalto.gov.br/ccivil_03/_ ato2019-2022/2019/decreto/D9759.htm. Acesso em: 07 jun. 2021.

${ }^{30}$ TEIXEIRA, Ana Claudia Chaves. Para além do voto: uma narrativa sobre a democracia participativa no Brasil (1975-2010). 2013. Tese (Doutorado) - Instituto de Filosofia e Ciências Humanas, Universidade Estadual de Campinas, Campinas, 2013. Disponível em: http://pct.capes.gov.br/teses/2013/33003017039P0/ TES.PDF. Acesso em: 10 mai. 2019.

${ }^{31}$ ALMEIDA, Carla; CAYRES, Domitila Costa; TATAGIBA, Luciana. Balanço dos estudos sobre os conselhos de políticas públicas na última década. Lua Nova, São Paulo, n. 94, p. 255-294, abr. 2015. Disponível em: http://www.scielo.br/scielo.php?script=sci_arttext\&pid=S0102-64452015000100009\&lng=en\&nrm=i so. Acesso em: 10 mai. 2019. http://dx.doi.org/10.1590/0102-64452015009400009.
} 
Não pode ser desconhecida a ênfase dada nessas décadas, e que acabou revelando-se uma armadilha, à participação social revestida de capacidade técnica - e não de capacidade de expressão de demandas e vontades políticas, setoriais e mais abrangentes -, reforçando-se a premissa de que a capacitação técnica dos conselheiros consistiria numa condição efetiva para se desenvolver o controle social na área da saúde e numa oportunidade de formar lideranças e usuários que, ao se apropriarem do enfoque teórico pertinente, contribuiriam para o equilíbrio de forças no interior dos conselhos ${ }^{32}$.

Não basta, no entanto, que se apontem acertos e erros internos do movimento sanitário brasileiro e de "sua criação"; torna-se necessário apontar um outro aspecto, sem o qual o SUS estará fadado à destruição. Não se pode esquecer que a proposta do governo atual (Jair Bolsonaro) é "ter muito para destruir", em particular o aparato do sistema de proteção social brasileiro, enquanto se assassina pelas bordas, a partir de reformas setoriais, a proposta constitucional de um sistema de seguridade social, "desconstitucionalizando" direitos sacramentados pela letra maior que rege o país.

Outro aspecto consiste no imperativo de se questionar até que ponto os militantes da saúde - profissionais, usuários e políticos, dentre outros - foram capazes de buscar o diálogo com os militantes dos demais setores da sociedade. Já foi apontado que a dimensão das conquistas institucionais e organizacionais do SUS tomou os espaços, corações e mentes de seus defensores e que, numa organização burocrática estatal segmentada em setores de atuação distintos, concorrentes entre si, sobretudo na área social, marcada pela precariedade de financiamento, os avanços da saúde acabaram sendo fruto não só da competência dos atores sociais envolvidos, mas também do fato de que, quando da elaboração da Constituição Federal de 1988, era o setor que se apresentava com a proposta mais acabada, embora ainda em construção, do que fazer para dar concretude à lei. Nesse sentido, o setor da saúde foi pioneiro, mas a luta pelos avanços institucionais cobrou seu preço: a competição por recursos públicos junto às demais políticas públicas de corte social e sua despolitização.

De fato, não há evidências de que a saúde enquanto direito de todos e dever do Estado, entendida como um bem público, nesses 30 anos tenha mobilizado de forma sustentada a sociedade em torno dessa questão social. Mobilizou seus militantes clássicos, mas perdeu fervor entre os sujeitos sociais mais coletivos e os segmentos organizados, seja no meio sindical, seja junto aos demais movimentos, como os que

${ }^{32}$ COTTA, Rosângela Minardi Mitre; CAZAL, Mariana de Melo; RODRIGUES, Jôsi Fernandes de Castro. Participação, controle social e exercício da cidadania: a (des) informação como obstáculo à atuação dos conselheiros de saúde. Physis, Rio de Janeiro, v. 19, n. 2, p. 419-438, maio 2009. Disponível em: http:// www.scielo.br/scielo.php?script=sci_arttext $\&$ pid=S0103-73312009000200010\&lng=en \&nrm=iso. Acesso em: 10 mai. 2019. http://dx.doi.org/10.1590/S0103-73312009000200010. 
lutam por habitação, pelo meio ambiente, pela terra. O que a RSB não conseguiu fazer, e isso na atualidade evidencia-se dramático, foi tornar a demanda pela saúde uma questão social coletiva, da sociedade civil em seu conjunto, ou mesmo das classes populares, e não circunscrita a determinados segmentos restritos da sociedade civil.

E se é consenso que a participação social via conselhos de saúde possibilitou a entrada de novos atores no cenário político, dando continuidade ao fenômeno que Eder Sader tão bem analisou sobre o movimento sindical e os movimentos sociais na periferia de São Paulo, nas décadas de 70 e 80 do século passado, agora a história se repete ${ }^{33}$. As vias institucionais de participação social, que vêm sendo extinguidas ou bloqueadas, precisam ser reconquistadas e que essa reconquista se insira na luta pela redemocratização do país. Dois fenômenos novos, no entanto, emergem: o autoritarismo com traços fascistas no seio de uma ordem formal e institucionalmente democrática; e a necessidade do enfrentamento do Estado como o inimigo ameaçador dos interesses populares e da sociedade em geral.

Com isso, retoma-se de certa forma a luta pela saúde como direito e pelo SUS num contexto, 30 anos depois, em que essa luta se dá num quadro de luta pela redemocratização da ordem social, política e econômica. Mais uma vez retorna com força a proposta de Arouca de que a luta pela saúde consiste num projeto civilizatório, de construção da civilidade na ordem social brasileira, aí incluída a solidariedade como fundamento do contrato social em (re)construção.

Os sujeitos sociais envolvidos no embate em defesa da saúde como um direito e seus parceiros potenciais eram, à época da RSB, passíveis de ser reconhecidos a partir de seu lugar social: assalariados (sindicalizados ou não), movimentos populares sem vínculos formais com o trabalho, intelectuais acadêmicos, setores progressistas da Igreja Católica, acadêmicos da área da saúde, profissionais da saúde organizados em seus órgãos de representação, dentre os principais; no entanto, essa base social não só foi sendo afastada (ou se afastando) do movimento da RSB, dada sua ênfase exacerbada (hoje é possível avaliar) na organização institucional, como também essas próprias bases sociais sofreram, no decorrer dessas décadas, profundas mudanças de toda natureza. Isto porque a proposta da RSB fundava-se em uma sociedade organizada no trabalho formal e, hoje, a sociedade brasileira está fundada na precariedade do trabalho. Não se trata somente de identificar os vínculos das classes sociais dos sujeitos envolvidos na luta pela reforma da saúde; o que está em jogo hoje é algo mais profundo e difuso, cujas bordas indefinidas dificultam a identidade social desses sujeitos e das lideranças da RSB.

Fleury e Paim, nos textos aqui já citados, alertam para a necessidade de retomar o discurso e a prática da construção de sujeitos de direito, constituídos a

\footnotetext{
${ }^{33}$ SADER, Eder. Quando novos personagens entraram em cena: experiências, falas e lutas dos trabalhadores da Grande São Paulo (1970- 1980). Rio de Janeiro: Paz e Terra, 1988.
} 
partir de ideologias, trabalho e lutas; mas o desafio que se apresenta é que, para tanto, há que buscar reconhecer as estruturas e os processos de formação desses sujeitos e dos movimentos sociais, marcados na atualidade, com raras exceções, pela defesa de interesses particulares, que, em sua radicalidade, impedem que sua representação seja fundada no interesse coletivo.

Como analisa Tatagiba ${ }^{34}$, o Brasil foi palco de uma mobilização social inédita em torno da questão da saúde como um direito, abarcando largo espectro político, porém essa agregação ainda não ganhou uma forma institucional nem foi capaz de dar à saúde a dimensão de bem público e universal, muito menos de fazer com que ocupasse um espaço de destaque no interior dos partidos políticos; as demandas da saúde equacionadas nesses termos são ainda, portanto, fragmentadas, sem uma direção política clara voltada à organização representativa. Tarefa tão mais complexa quando, em 2019, foi revogado o Decreto 8.243/2014, que instituiu a Política Nacional de Participação Social (PNSP), fruto de um intenso processo de debate, em vários espaços, dentre eles no I Seminário Nacional de Participação Social, realizado em $2011^{35}$.

Paralelamente, os gestores, pressionados pela demanda junto aos serviços de saúde em um contexto de progressiva escassez e contingenciamento de recursos, acabam por assumir o papel não mais de apoiadores intransigentes da RSB, tal como no passado, mas na prática do SUS. No mesmo ambiente, encontram-se os trabalhadores da saúde, cada vez mais pressionados pela precariedade de seus vínculos de trabalho e pela realidade da crescente presença das organizações sociais na gestão dos serviços públicos, sendo progressivamente transformados de trabalhadores da saúde em meros "colaboradores". Nessa condição, o vínculo já precário entre trabalhadores da saúde e sua clientela (usuários do SUS), sobretudo marcado pela alta rotatividade, torna-se cada vez mais tênue. Assim, em sua militância esses trabalhadores tendem a restringir o âmbito de luta em defesa do SUS - o que, se não é de pouca monta, significa ao mesmo tempo a perda da dimensão mais ampla da luta política que vem significando a RSB.

Há que se resgatar, portanto, não a simples capacitação desses profissionais nas habilidades técnicas para o exercício de suas atividades, mas sua formação para o trabalho em um ambiente público. Essa formação, que constituiu parte central dos esforços de implantação e implementação do SUS no atual contexto, reveste-se de um teor revolucionário. Daí a razão de retomar aqui um dos pensadores fundantes da RSB, Ricardo Bruno Mendes Gonçalves, em sua brilhante análise sobre tecnologia e organização social das práticas de saúde, quando afirma:

\footnotetext{
${ }^{34}$ TATAGIBA, Luciana. op. cit., p. 71-98.

${ }^{35}$ OLIVEIRA, O Porto de; RODRIGUES, M.; BARONE, Leonardo Silva; VOIGT, Jessica. Relatório do I Seminário Nacional de Participação Social. São Paulo: Centro Brasileiro de Análise e Planejamento, 2011.
} 
O processo de trabalho não é apenas dispêndio mecânico de forças: é a forma mais especialmente humana de sociabilidade, de gênese histórica. Em cada grão de tecnologia estão contidas, assim, ao mesmo tempo, todas as determinações do passado que nela desembocam e toda a construção viva do futuro ${ }^{36}$.

\section{Considerações finais}

Cabe alinhavar alguns pontos para serem objeto de reflexão no enfrentamento da atual conjuntura, tão desfavorável para a democratização da saúde e sua construção enquanto um direito social. Repensar criticamente as teorias sobre a Reforma Sanitária Brasileira é imprescindível. Para tanto, resgatar velhas explicações sobre a RSB e a realidade brasileira torna-se imprescindível sem, no entanto, desprezar o que já foi construído e elaborado.

A disposição para enfrentar a nebulosidade do momento presente igualmente exige coragem. De um lado, porque não se trata somente de buscar pistas para, a partir do Estado, promover a construção do SUS, mas também de ter a clareza de que a relação Estado/sociedade/mercado não pode ser abordada como antes, privilegiando-se o Estado como principal ator e mentor da mudança social. A atual conjuntura demanda mais: demanda que se enfrente a realidade de que à crise econômica e política associa-se uma crise social, revelando com toda sua crueza uma sociedade constituída por segmentos sociais - que não se restringem às elites - extremamente autoritários.

Não se trata mais, no esforço de buscar potenciais atores que comunguem propostas progressistas para a saúde, os direitos sociais e os direitos humanos, de pensar frações de classes, os inseridos e os não inseridos no mercado de trabalho, mas de reconhecer que a sociedade brasileira atual está fragmentada entre ricos e pobres - entendendo os ricos como os não pobres, ou seja, aqueles com acesso ao mercado, mesmo que na saúde esse acesso ocorra por meio de precários planos populares de saúde, por exemplo. Assumir como núcleo da reflexão voltada para a ação o fato de que o sistema público de saúde não se reduz ao componente do subsistema estatal, mas compreende também o sistema privado complementar - o que já vem sendo explicitado, embora um pouco envergonhadamente ainda, por alguns reformistas sanitários. Ou seja, reconhecer que efetivamente o sistema privado enquanto complementar ao sistema público, como está na lei, é uma realidade que deve ser absorvida como tal, na busca de um difícil contrato entre os dois sistemas que seja liderado pela lógica do setor público para que não seja perverso ${ }^{37}$. A questão

\footnotetext{
${ }^{36}$ GONÇALVES, Ricardo Bruno Mendes. Tecnologia e organização social das práticas de saúde: características tecnológicas do processo de trabalho em saúde na rede estadual de centros de saúde de São Paulo. São Paulo: HUCITEC-ABRASCO, 1994. p. 268.

${ }^{37}$ TEMPORÃO, José Gomes. Para onde vai o SUS? Brasília: Conselho Nacional de Secretários de Saúde CONASS, 2014.
} 
fundamental consiste em como, nessa atual composição público/privado em que ambos se confundem ${ }^{38}$, seria possível reconquistar a hegemonia da razão pública frente à privada, sobretudo num contexto em que há no setor privado, supletivo e complementar a forte presença do capital estrangeiro e do setor financeiro ${ }^{39}$.

Trazendo novamente à baila as análises de Paim, para quem a RSB é cria do movimento sanitário, e aqui afirmando que o SUS é cria de ambos, a questão de fundo que incita a reflexão e a ação é: aproveitando a experiência pregressa da luta pela saúde como um direito universal e equânime, neste contexto de investidas contra a ordem democrática, não seria o caso de retomar a saúde enquanto questão social no interior dos movimentos de resistência democrática ora em tela? A partir de 1975, a saúde revelou-se como um fator de organização e mobilização da sociedade em termos pontuais, embora sem dúvida fundamentais, tal como atesta a história; mas a saúde revelou-se igualmente incapaz de uma mobilização de longo prazo que envolvesse as massas sociais. A crescente desmobilização e restrição dos quadros sociais no apoio à saúde mostra isso, bem como a identificação dos profissionais da saúde como trabalhadores do SUS, e não como militantes da reforma sanitária, tendendo a descolar uma coisa da outra.

Num contexto em que se trata de forjar uma reação para que a democracia não seja destruída por forças conservadoras e predatórias, a saúde merece atenção especial enquanto questão social, parceira das demais questões sociais, capaz de com elas dialogar e formar uma força social que aglutine os segmentos sociais identificados com uma ordem social democrática e igualitária. No entanto, se alguma lição ficou da experiência pregressa da RSB, ela consiste em que isoladamente a saúde perdeu seu pioneirismo na luta pela conquista dos direitos sociais, talvez porque tenha se resignado às conquistas iniciais, servindo inclusive de modelo para os demais setores de políticas públicas.

Diante da urgência de que os princípios e diretrizes do SUS não se percam na atual conjuntura desfavorável a políticas sociais que resgatem a cidadania e o Estado democrático de direito, as novas janelas de oportunidade para retomar a RSB residem na busca da reconquista da identificação e do diálogo com as novas formas de estruturação e constituição de sujeitos sociais comprometidos com a questão da saúde como um direito, e não como um bem de consumo. E que se enfrente a questão de até que ponto experiência brasileira, a partir dos anos 1990 e sobretudo nas décadas iniciais deste século, em particular na área da saúde, governos de coalizão com propostas redistributivas na área social revelaram-se suficientes para o enfrentamento da ferocidade das elites brasileiras, resistente a que espaços sociais que até então foram seu monopólio sejam partilhados pelas classes subalternas.

\footnotetext{
${ }^{38} \mathrm{COHN}$, Amélia. A reforma sanitária brasileira após 20 anos do SUS: reflexões. Cad. Saúde Pública, Rio de Janeiro, v. 25, n. 7, p. 1614-1619, jul. 2009. Disponível em: http://www.scielo.br/pdf/csp/v25n7/20. Acesso em: 10 mai. 2019.

${ }^{39}$ SCHEFFER, Mário. O capital estrangeiro e a privatização do sistema de saúde brasileiro. Cad. Saúde Pública, Rio de Janeiro, v. 31, n. 4, abril 2015. Disponível em: https://www.scielosp.org/scielo.php?pid=S0102311X2015000400663\&script=sci_arttext. Acesso em: 16 dez. 2019.
} 


\section{Referências}

ALMEIDA, Carla; CAYRES, Domitila Costa; TATAGIBA, Luciana. Balanço dos estudos sobre os conselhos de políticas públicas na última década. Lua Nova, São Paulo, n. 94, p. 255-294, abr. 2015. Disponível em: http://www.scielo.br/scielo.php?script=sci_arttext\&pid=S010264452015000100009\&lng=en\&nrm=iso. Acesso em: 10 mai. 2019. http://dx.doi. org/10.1590/0102-64452015009400009.

AROUCA, Antônio Sérgio da Silva. Deu certo! Saúde Debate, Rio de Janeiro, v. 28, p. 75-77, 2003.

BAHIA, Ligia; SCHEFFER, Mario. O SUS e o setor privado assistencial: adaptações e contradições. Saúde Debate, Rio de Janeiro, v. 42, n. especial 3, p. 158-171, nov. 2018. Disponível em: http://www.scielo.br/scielo.php?script=sci_arttext\&pid=S0103-11042018000700158\&ln $\mathrm{g}=\mathrm{en} \& \mathrm{nrm}=$ iso. Acesso em: 10 mai. 2019. http://dx.doi.org/10.1590/0103-11042018s312.

COHN, Amélia. "Caminhos da reforma sanitária”, revisitado. Estud Av, São Paulo, v. 32, n. 93, p. 225-241, ago. 2018. Disponível em: http://www.scielo.br/scielo.php?script=sci_ arttext\&pid=S0103-40142018000200225\&lng=pt\&nrm=iso. Acesso em: 10 mai. 2019. https:// dx.doi.org/10.5935/0103-4014.20180040.

COHN, Amélia. A reforma sanitária brasileira após 20 anos do SUS: reflexões. Cad. Saúde Pública, Rio de Janeiro, v. 25, n. 7, p. 1614-1619, jul. 2009. Disponível em: http://www.scielo. br/pdf/csp/v25n7/20. Acesso em: 10 mai. 2019.

COTTA, Rosângela Minardi Mitre; CAZAL, Mariana de Melo; RODRIGUES, Jôsi Fernandes de Castro. Participação, controle social e exercício da cidadania: a (des) informação como obstáculo à atuação dos conselheiros de saúde. Physis, Rio de Janeiro, v. 19, n. 2, p. 419-438, maio 2009. Disponível em: http://www.scielo.br/scielo.php?script=sci_arttext\&pid=S010373312009000200010\&lng=en\&nrm=iso. Acesso em: 10 mai. 2019. http://dx.doi.org/10.1590/ S0103-73312009000200010.

ESCOREL, S.; NASCIMENTO, D. R.; EDLER, F. C. As origens da reforma sanitária e do SUS. In: LIMA, Nísia Trindade; GERSCHMAN, Silvia; EDLER, Flavio Coelho; SUÁREZ, Julio Manuel (Orgs.). Saúde e democracia: história e perspectivas do SUS. Rio de Janeiro: Editora Fiocruz, 2005. p. 59-81.

ESCOREL, Sarah. Reviravolta na saúde: origem e articulação do movimento sanitário, 1. ed. Rio de Janeiro: Fiocruz, 1999.

FERNANDES, Florestan. A revolução burguesa no Brasil. Rio de Janeiro: Zahar, 1975.

FERTONANI, Hosanna Pattrig; PIRES, Denise Elvira; BIFF, Daiane; SCHERER, Magda Duarte dos Anjos. The health care model: concepts and challenges for primary health care in Brazil. Ciênc Saúde Coletiva, Rio de Janeiro, v. 20, n. 6, p. 1869-1878, jun. 2015. Disponível em: http://www.scielo.br/scielo.php?pid=S1413-81232015000601869\&script=sci_abstract. Acesso em: 10 mai. 2019. http://dx.doi.org/10.1590/1413-81232015206.13272014.

FLEURY, Sonia. (Org.). Teoria da reforma sanitária brasileira: diálogos críticos. Revisitar a teoria e a utopia da reforma sanitária. Rio de Janeiro: Fiocruz, 2018. p. 31-84. 
GONÇALVES, Ricardo Bruno Mendes. Tecnologia e organização social das práticas de saúde: características tecnológicas do processo de trabalho em saúde na rede estadual de centros de saúde de São Paulo. São Paulo: HUCITEC-ABRASCO, 1994.

INSPER. Judicialização da saúde no Brasil: perfil das demandas, causas e propostas de solução. Brasília: Instituto de Ensino e Pesquisa -2019. (Relatório Analítico Propositivo Justiça Pesquisa). Disponível em: https://static.poder360.com.br/2019/03/relatorio-judicializacaosaude-Insper-CNJ.pdf. Acesso em: 15 abr. 2019.

MATHIAS, Maíra. Uma segunda alma para o SUS? Entidades criadas por empresários da saúde abrem caminho para um Sistema Único totalmente integrado e gerido pelo setor privado. Escola Politécnica de Saúde Joaquim Venâncio, 09 nov. 2016. Disponível em: http://www.epsjv. fiocruz.br/noticias/reportagem/uma-segunda-alma-para-o-sus. Acesso em: 12 maio 2019.

MBEMBE, Achille. Necropolítica. São Paulo: N-1 edições, 2018.

MENDES, Eugenio Vilaça. A construção social da atenção primária à saúde [online]. Brasília: Conselho Nacional de Secretários de Saúde - CONASS, 2015. Disponível em: http://www. saude.go.gov.br/wp-content/uploads/2016/12/a-construcao-social-da-atencao-primaria-asaude.pdf. Acesso em: 20 abr. 2019.

OLIVEIRA, Jaime A. A saúde pública hoje: notas para um debate sobre a conjuntura em saúde e a situação da ENSP ao seu interior. Cad. Saúde Pública, Rio de Janeiro, v. 4, n. 3, p. 326-333, set. 1988. Disponível em: http://www.scielo.br/scielo.php?script=sci arttext\&pid=S0102-311X1988000300007. Acesso em: 10 mai. 2019. http://dx.doi.org/10.1590/ S0102-311X1988000300007.

OLIVEIRA, O Porto de; RODRIGUES, M.; BARONE, Leonardo Silva; VOIGT, Jessica. Relatório do I Seminário Nacional de Participação Social. São Paulo: Centro Brasileiro de Análise e Planejamento, 2011. Disponível em: http://www.secretariadegoverno.gov.br/ participacao-social/seminario/relatorio-final. Acesso em: 13 mai. 2019.

PAIM, Jairnilson da Silva. A reforma sanitária brasileira e o Sistema Único de Saúde: dialogando como hipóteses concorrentes. Physis, Rio de Janeiro, v. 18, n. 4, p. 625-643, 2008. Disponível em: http://www.scielo.br/scielo.php? script=sci_arttext\&pid=S010373312008000400003\&lng=en\&nrm=iso. Acesso em: 10 maio 2019 http://dx.doi.org/10.1590/ S0103-73312008000400003.

PAIM, Jairnilson da Silva. Reforma sanitária brasileira: contribuição para a compreensão e crítica. Salvador: EDUFBA/Rio de Janeiro: FIOCRUZ, 2008. Disponível em: http://books. scielo.org/id/4ndgv/pdf/paim-9788575413593.pdf. Acesso em: 26 mar. 2019.

PAIM, Jairnilson da Silva. Sistema Único de Saúde (SUS) aos 30 anos. ABRASCO. 30 anos do Sistema Único de Saúde (SUS). Ciência e Saúde Coletiva, Rio de Janeiro, v. 23, n. 6, p. 1723-1728, jun. 2018.

PAIM, Jairnilson da Silva. Sujeitos da antítese e os desafios da práxis da reforma sanitária brasileira. In: FLEURY, Sonia (Org.). Teoria da reforma sanitária brasileira: diálogos críticos. Rio de Janeiro: Fiocruz, 2018. p. 115-144. 
PAIVA, Carlos Henrique Assunção; TEIXEIRA, Luís Antonio. Reforma sanitária e a criação do Sistema Único de Saúde: notas sobre contextos e autores. Hist, Ciênc, Saúde-Manguinhos, Rio de Janeiro, v. 21, n. 1, p. 15-35, jan./mar. 2014. Disponível em: http://www.scielo.br/pdf/ hcsm/v21n1/0104-5970-hcsm-21-1-00015.pdf. Acesso em: 10 mai. 2019.

SADER, Eder. Quando novos personagens entraram em cena: experiências, falas e lutas dos trabalhadores da Grande São Paulo (1970- 1980). Rio de Janeiro: Paz e Terra, 1988.

SCHEFFER, Mário. O capital estrangeiro e a privatização do sistema de saúde brasileiro. Cad. Saúde Pública, Rio de Janeiro, v. 31, n. 4, abril 2015. Disponível em: https://www.scielosp.org/ scielo.php?pid=S0102-311X2015000400663\&script=sci_arttext. Acesso em: 16 dez. 2019.

SESTELO, José Antonio de Freitas. Planos e seguros de saúde do Brasil de 2000 a 2015 e a dominância financeira. 2017. Tese (Doutorado) - Programa de Pós-Graduação em Saúde Coletiva, Universidade Federal do Rio de Janeiro, Rio de Janeiro, 2017. Disponível em: http:// www.iesc.ufrj.br/gpdes/images/arquivos/Tese---Jos-Sestelo.pdf. Acesso em: 10 mai. 2019.

SILVEIRA, Lucas Bronzato. A produção teórica da saúde coletiva brasileira na década de 90: texto, contexto e mudança social. 2015. Dissertação (Mestrado) - Escola Nacional de Saúde Pública Sergio Arouca, Fundação Oswaldo Cruz, Rio de Janeiro, 2015. Disponível em: https:// www.arca.fiocruz.br/handle/icict/13476. Acesso em: 10 mai. 2019.

STREECK, Wolfgang. The crisis of democratic capitalism. New Left Review, Reino Unido, v. 71, p. 5-29, set.-out. 2011. Disponível em: https://newleftreview.org/issues/II71/articles/ wolfgang-streeck-the-crises-of-democratic-capitalism. Acesso em: 10 mai. 2019.

TATAGIBA, Luciana. Os protestos e a crise brasileira. Um inventário inicial das direitas em movimento (2011-2016). Sinais Sociais, Rio de Janeiro, v. 11, n. 33, p. 71-98, jan./abr. 2017. Disponível em: http://www.sesc.com.br/wps/wcm/ connect/3daaa858-e528-4f0b-b12a-e115803bf073/SinaisSociais_SS33_WEB_14_09_17. pdf?MOD=AJPERES\&CACHEID=3daaa858-e528-4f0b-b12a-e115803bf073. Acesso em: 10 mai. 2019.

TEIXEIRA, Ana Claudia Chaves. Para além do voto: uma narrativa sobre a democracia participativa no Brasil (1975-2010). 2013. Tese (Doutorado) - Instituto de Filosofia e Ciências Humanas, Universidade Estadual de Campinas, Campinas, 2013. Disponível em: http://pct. capes.gov.br/teses/2013/33003017039P0/TES.PDF. Acesso em: 10 mai. 2019.

TEMPORÃO, José Gomes. Para onde vai o SUS? Brasília: Conselho Nacional de Secretários de Saúde - CONASS, 2014. 
Cohn A., Gleriano J. S.

Amélia Cohn - Doutorado em Sociologia pela Universidade de São Paulo (USP); mestrado em Sociologia pela USP; graduação em Ciências Sociais pela USP. Professora do Programa de Mestrado em Direito da Saúde: Dimensões Individuais e Coletivas da Universidade Santa Cecília (Unisanta).Santos/SP, Brasil.E-mail:cohn.amel@gmail.com

Josué Souza Gleriano - Doutorando pelo Programa de Pós-Graduação em Enfermagem Fundamental da Escola de Enfermagem de Ribeirão Preto da Universidade de São Paulo (EERP/USP). Professor na área de políticas de saúde no Departamento de Enfermagem na Universidade do Estado de Mato Grosso. Tangará da Serra/MT, Brasil.E-mail: josue_gleriano@ hotmail.com 